\title{
Climate Change and Aerosol Sciences
}

\author{
Kehan Li ${ }^{1}$
}

\begin{abstract}
Climate change is of great importance in modern times and global warming is considered as a significant part of climate change. It is proved that human's emissions such as greenhouse gases are one of the main sources of global warming (IPCC, 2018). Apart from greenhouse gases, there is another kind of matter being released in quantity via emissions from industries and transportations and playing an important role in global warming, which is aerosol. However, atmospheric aerosols have the net effect of cooling towards global warming. In this paper, climate change with respect to global warming is briefly introduced and the role of aerosols in the atmosphere is emphasized. Besides, properties of aerosols including dynamics and thermodynamics of aerosols as well as interactions with solar radiation are concluded. In the end, environmental policies and solutions are discussed.
\end{abstract}

Keywords: Climate change, Global warming, Atmospheric aerosols, Particulate matter, Radiation, Environmental policy.

${ }^{1}$ University of Reading, Whiteknights, Reading RG6 6ET, United Kingdom.

Article Info: Received: January 13, 2021. Revised: January 31, 2021.

Published online: February 2, 2021. 


\section{Global Warming Introduction with Atmospheric Chemistry and Physics}

\subsection{Climate Change Introduction}

Due to human activities, the earth has become warmer by $1{ }^{\circ} \mathrm{C}$ compared to that in the pre-industrial time, with a likely range of 0.8 to $1.2^{\circ} \mathrm{C}$. It is strongly believed that global warming will keep proceeding by human and is going to reach $1.5{ }^{\circ} \mathrm{C}$ from 2030 to 2052 (IPCC, 2018). The main cause for global warming is the massive exhausts and pollutants, which contain much greenhouse gas and aerosols, emitted by industries and human's daily life such as transportation and heating. The World Meteorological Organization evaluated that the concentrations of $\mathrm{CO} 2$ and methane had increased by about $45 \%$ and $160 \%$, respectively in 2018 since the pre-industries times. The increasing concentrations of GHG absorb more long-wave radiation emitted by the earth and thus global warming occurs. Apart from GHG warming mechanism, there are some other ways which can also lead to global warming such as solar and volcanic activities (Stone et al, 2007). To be more specific, the pollutants or the sources that are likely to cause air pollution or global warming are different in remote area and in urban as hotspot. In the urban areas, the pollutants are mainly from traffic, combustion and agriculture, domestic fuel burning and industrial activities (Karagulian et al, 2015). It can be said that almost all the pollutants in cities are generated by human activities. However, in the remote areas like depopulated zones and oceans, there are still some pollutants generated but they are not that much compared to those in urbans. The sources can be dust, methane emitted by animals, smoke and carbon monoxide from wildfires, and sulfur dioxide, carbon dioxide, and hydrogen fluoride from volcanic activities (Stone et al, 2007) (Finlay et al, 2012).

Although global warming can be possibly caused naturally, it is proved that, after the industrial revolution (particularly from 1889 to 2006), humans account for approximately $80 \%$ of the observed warming on the earth (Lean and Rind, 2008; Stott et al, 2010). In this situation, aerosols, which are parts of fundamental elements in the atmosphere and can interact with radiations from both the sun and the earth, are going to be more and more significant for humans to analyze what kind of role aerosols play under the background of global warming.

Aerosols actually have a net cooling effect on the climate, from the both aspects of direct radiative effect and indirect radiative effect. Aerosols can absorb the radiation and heat the surroundings but they can also block the radiation. The net effect of the direct radiative effect turns out to be cooling and this cooling effect is increased by global warming (Allen et al, 2016). Additionally, aerosols can induce cloud formation and thus block the radiation from the solar. As a result, the indirect radiative effect is also a cooling effect and even stronger than the direct radiative effect (Allen et al, 2016). Furthermore, global warming associated with greenhouse gas is likely to increase the aerosol burden of both nature and man-made, which will consequently enhance the cooling effects of aerosols (Allen et al, 2016). On the other hand, these aerosols are increasing the uncertainty of global climate. Due to 
the short life-time and variable emissions of aerosols, scientists find it difficult to predict how the global climate may change and the extent of global warming in the future (Andreae et al, 2005).

\subsection{Atmospheric Radiation and Photochemistry}

Atmospheric radiation plays an important role in the energy balance for the earth system. Basically, all energy on the earth comes from the sun. The radiation from the sun reaching the earth is approximately $1370 \mathrm{~W} / \mathrm{m}^{2}$ (Hickey et al, 1988), which is called the solar constant. After reaching the earth (top of atmosphere), the radiation will go through some processes which are shown on the Figure 1.

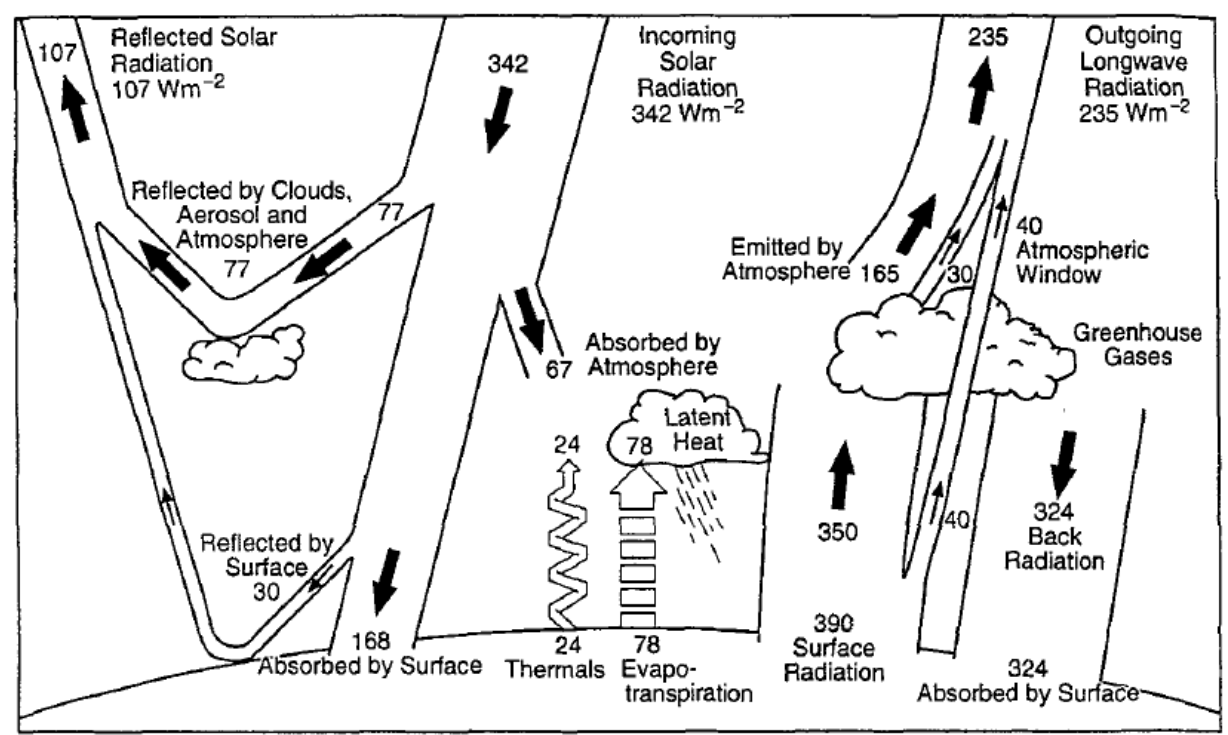

Figure 1: The Earth's annual and global mean energy balance (Kiehl and Trenberth, 1997)

As is shown in Figure 1, the atmosphere 'gives back' a large proportion of terrestrial radiation to the ground, which helps keep the earth warm. The more GHG in the atmosphere, the more radiation can the atmosphere hold and thus the warmer is the earth. Also, air pollution in regard of exhaust including chemical gases and fine particles will make a difference on atmospheric radiation and thus lead to climate change.

Atmospheric photochemistry is important in the stratosphere and upper troposphere where the ozone is mainly found. With a visible or ultra-violet photon, ozone dissociates into an oxygen molecule and an oxygen atom. Since these oxygen atoms combine with oxygen molecules to reform ozone with heat release, the reaction between ozone and oxygen merely converts light into heat. However, chlorofluorocarbons (CFCs) are destructive to ozone. For instance, the chlorine from the CFCs will wipe out ozone in the process shown below (Equation 1). 


$$
\begin{aligned}
& \mathrm{O}_{3}+\mathrm{Cl} \longrightarrow \mathrm{ClO}+\mathrm{O}_{2} \\
& \mathrm{ClO}+\mathrm{O} \longrightarrow \mathrm{O}_{2}+\mathrm{Cl}
\end{aligned}
$$

In this process, chlorine acts as a catalyzer. Once the CFCs are discharged into atmosphere, they will go up to the stratosphere and upper troposphere and exist there for decades (Elkins et al, 1993). Therefore, a large amount of ozone will be destroyed by these CFCs. Though it has been argued whether ozone depletion would enhance or reduce global warming, NASA reported that there was no enough evidence showing the ozone depletion was related with climate change (Bowden and John, 2019).

\subsection{Atmospheric Aerosols}

Atmospheric aerosol is a particulate matter (PM), including fine solid and liquid particles, suspending in the atmosphere. The sources of atmospheric aerosols can be made by nature and human. Sea salt, desert dust and volcanic eruption are the sources of natural atmospheric aerosols while burning fossil fuel is the main way in which anthropogenic aerosols are produced (Rabha and Saikia, 2020). As fundamental elements in the atmosphere, aerosols play an important role in impacting climate. On one hand, aerosols are particles then they can absorb or reflect the radiation from both solar and the earth. Therefore, they are able to heat or cool the environment. On the other hand, after the aerosol particles become moist enough, they will become cloud condensation nuclei and eventually form clouds in the atmosphere. As a result, they will scatter the light and changing Earth's reflectivity. If the concentration of aerosols increases, the reflectivity of Earth will increase (Christensen et al, 2016). The mechanisms of how aerosols interact with radiation and how they influence our climate will be discussed in section 2.4.

\section{Aerosol science and interaction}

\subsection{Properties of atmospheric aerosols}

Atmospheric aerosols have a large range of their sizes or diameters though they are tiny, which is described using the size distribution function of aerosols. The size distribution is very crucial to analyze the influences that aerosols have on the climate because the lifetime of aerosols and their physical and chemical properties depend on the size (Seinfeld and Pandis, 2006). For instance, Sub-micrometer aerosols scatter more light per unit mass and are able to exist longer in the atmosphere than larger aerosols (Andreae et al, 2001). The aerosol size is measured by light scattering optical particle counters widely and the size distributions can be obtained by the program in the instruments after measuring (Liu et al, 1985). 

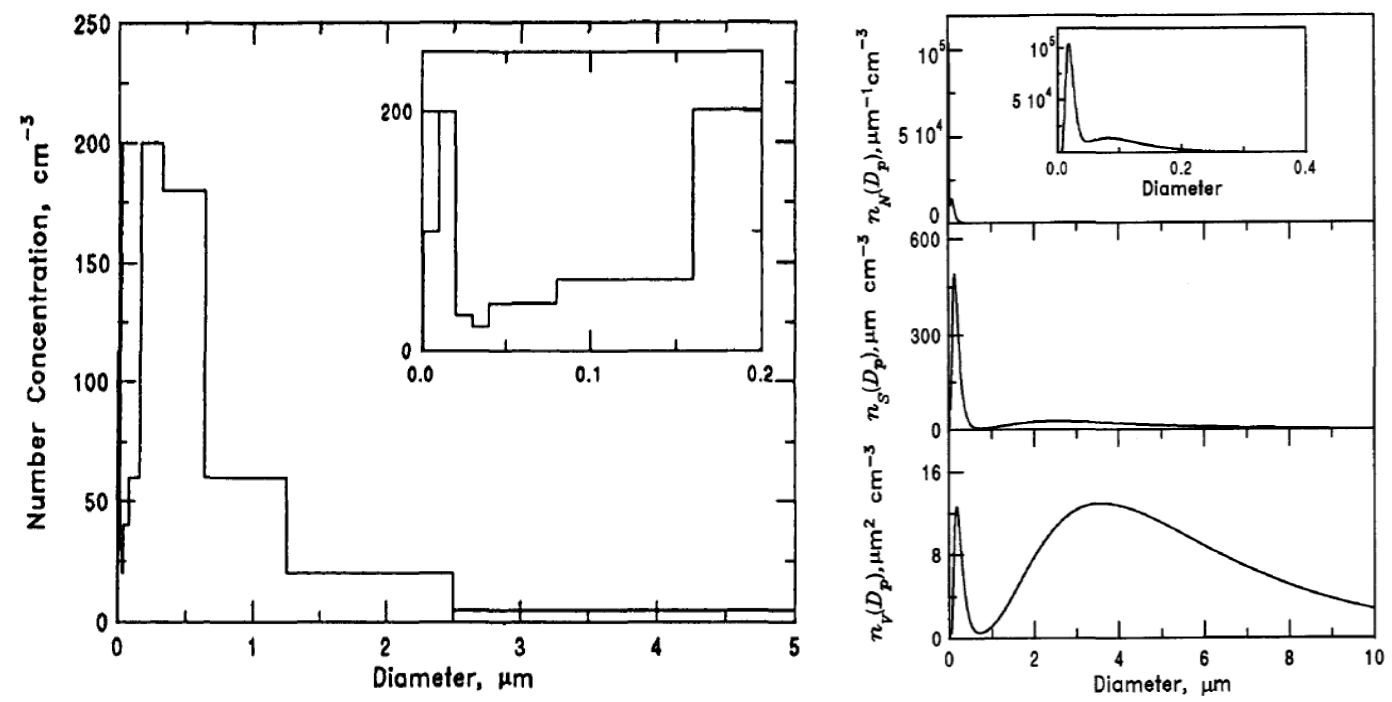

(Left) Figure 2: Histogram of aerosol particle number concentrations versus the size range for the distribution of an example of segregated aerosol size information. The diameter range $0-0.2 \mu \mathrm{m}$ for the same distribution is shown in the inset. (Seinfeld and Pandis, 2006)

(Right) Figure 3: Atmospheric aerosol number, surface, and volume continuous distributions versus particle size. The diameter range 0-0.4 $\mu \mathrm{m}$ for the number distribution is shown as an inset. (Seinfeld and Pandis, 2006)

Apart from size distribution, distributions from other perspectives are used to describe the properties of atmospheric aerosols such as number, surface area, volume and mass distributions.

With all kinds of distribution functions, atmospheric aerosols in the research region are well-described and their properties can be deduced.

\subsection{Dynamics of Single Aerosol Particles}

Although aerosol particles are fine particles, each of them can be seen as independent. Therefore, every single aerosol particle has its own force conditions and motion. The dynamics of aerosols can be divided into two conditions: continuum or non-continuum dynamics. These two conditions are distinguished by the mean free path which is defined as the average distance traveled by a molecule between collisions with other molecules. If the particle size is larger than the mean free path of the surrounding molecules, the fluid made up by the particles is considered as continuous fluid. Otherwise, the fluid is considered as discontinuous fluid. Therefore, different theories according to continuous fluid or discontinuous fluid can be applied to research (Seinfeld and Pandis, 2006).

Each aerosol particle is also affected by the drag force (viscous force), considering the fluid is not inviscid in real world. The drag force depends on the viscosity 
coefficient of the fluid and the velocity of the fluid, which can be conducted by the Stokes' law $F_{d}=6 \pi \mu R v$, where $\mu$ the viscosity coefficient, $R$ radius of the particle and $v$ the flow velocity relative to the particle (Laidler and Meiser, 1982). This is the situation where Reynolds number is much smaller than $1(\operatorname{Re}<<1)$, or the drag force dominates the inertial force in the fluid. However, when Reynolds number is larger or close to 1 ( $\operatorname{Re} \sim 1$ or $\operatorname{Re}>>1$ ), Stokes' law needs correction, $F_{d}=\frac{1}{8} \pi C_{D} \rho D_{p}{ }^{2} u_{\infty}{ }^{2}$, where $\rho$ the density of the fluid, $D_{p}$ the diameter, $u_{\infty}$ the velocity of the fluid and $C_{D}$ the function of Reynolds number. To conclude, for aerosols and most cloud droplets $(\operatorname{Re}<<1$ ), Stokes' law describes the drag force on particle, but for large cloud droplets or raindrops $(\operatorname{Re} \sim 1$ or $\operatorname{Re}>>1)$, Stokes' law underestimate the drag force and correction should be conducted to the law (Seinfeld and Pandis, 2006).

In addition, external forces such as gravitational force, electrical force and phoretic force may exert on the aerosol particles and cause migration (Hidy, 1984). Nevertheless, it is sufficient for most atmospheric applications if we neglect gravitational force and particle inertia leads to the zero-order approximation which means particle follows the streamlines of the airflow (Seinfeld and Pandis, 2006). Up to this point, many features of aerosols are figured out, depending on their diameters or radiuses. However, a large proportion of particles in the atmosphere are not spherical so their diameters are not able to be determined in a traditional way. Under this situation, the concept of equivalent particle diameters is defined for the non-spherical particles or even for the spherical particles of unknown density or charge (Seinfeld and Pandis, 2006). The non-spherical particles with equivalent diameter will yield the same size measurement with the spherical particles in this diameter. Additionally, the shape factor was defined by Fuchs in 1964 as the ratio of actual drag force on the non-spherical particle to the drag force on the spherical particle with the diameter equal to the volume equivalent diameter of the nonspherical particle, in order to make the shape effect during the flow into account.

\subsection{Thermodynamics of Aerosols}

Atmospheric aerosols contain inorganic salts and at very low relative humidity the salts are solid. When the relative humidity increases and once it reaches a threshold value which is known as deliquescence relative humidity (DRH), the solid particles of the aerosols begin to absorb water and become a saturated aqueous solution. Besides, the DRH for single salt varies with temperature (Seinfeld and Pandis, 2006). The situation is similar if the aerosol contain more than one component of salt except how the value of DRH may vary: the DRH of a multicomponent aerosol is always lower than the DRH of each single-component aerosol (Seinfeld and Pandis, 2006). Therefore, the multicomponent aerosols are more likely to absorb water in the air and become cloud droplets at lower relative humidity.

On the other hand, when the relative humidity is very low, the water absorbed by the salt will begin to evaporate and the salt will become dry. The relative humidity where the aerosol particles become dry is defined as the efflorescence relative 
humidity (ERH). Unlike the DRH, the ERH can not be simply calculated by thermodynamic principles. It can only be obtained by measurement in the laboratory (Seinfeld and Pandis, 2006). Besides, aerosols of multi-component salts have a much more complicated behavior of efflorescence, showing different steps of changes during the process of efflorescence. For instance, the efflorescence process of particles containing $\mathrm{KCl}$ and $\mathrm{NaCl}$ have two step changes: the first at $65 \% \mathrm{RH}$ with the formation of $\mathrm{KC} 1$ crystals and the second at $62 \% \mathrm{RH}$ with the complete drying of the particles and the crystallization of the remaining $\mathrm{NaCl}$ (Martin, 2000). As for the ERH of particles with multi types of salt, it depends on the composition of the particles (Seinfeld and Pandis, 2006).

When an aerosol particle literally becomes a droplet with liquid water covered, the vapor pressure around the droplet which has a curved interface with air is always greater than that over a flat surface. The Kelvin Effect accounts for this phenomenon (Seinfeld and Pandis, 2006).

\subsection{Interactions of Aerosols with Radiation}

There are four aspects of interactions of aerosols with radiation in general: reflection, absorption, scattering and emission. Since scattering is considered to be more important and complicated among these interactions, it will be emphatically discussed in this paper. When the radiation reaches to the aerosol particles, part of the radiation will be reflected and scattered. The remain radiation will be possibly absorbed by the particles and converted into other forms of energy. The scattering of radiation can be divided into three regimes depending on the wavelength of incident radiation and the size of aerosol particles as is shown in the (Equation 2) below:

$$
\alpha=\frac{\pi D_{p}}{\lambda}
$$

(Bohren and Huffman, 1983)

where $D_{p}$ is the diameter of the particle and $\lambda$ is the wavelength of incident radiation.

For $\alpha \ll 1$, it means the particle is too small compared to the wavelength of radiation so the Rayleigh scattering regime (shown in Figure 4) will dominate the scattering. The intensity of scattering is symmetrical in forward and backward directions and independent of particle shape, but the scattering efficiency varies inversely with the fourth power of the wavelength (Young, 1981). For $\alpha \sim 1$ which means the aerosol particle is about the same size as the wavelength of radiation, the Mie scattering will be dominant. The Mie scattering has the light scattered more in the forward direction and even sharper and stronger for larger particles, shown in Figure 4 (Nave, 2001). 


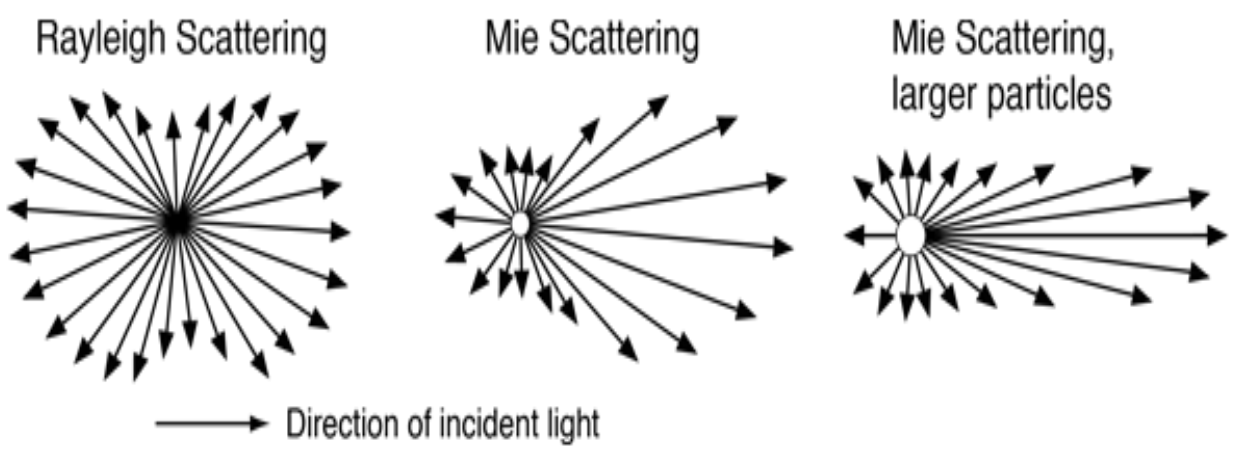

\section{Figure 4: Angular distribution of scattered light by Rayleigh and Mie scattering (Nave, 2001)}

For $\alpha \gg 1$ which means the particle is very large compared to the wavelength of radiation, the scattering is closely related to particle shape and direction of incoming light (Bohren and Huffman, 1983). This kind of scattering can be determined on the basis of the geometrical optics of reflection, refraction, and diffraction (Bohren and Huffman, 1983). About how the light is scattered, the scattering phase function is introduced to describe the angular distribution of light intensity scattered by a fine particle at a given wavelength (Seinfeld and Pandis, 2006), shown below in (Equation 3).

$$
P(\theta)=\frac{F(\theta)}{\int_{0}^{\pi} F(\theta) \sin \theta d \theta}
$$

where $F$ is the intensity or radiance, $P$ is the probability density function showing the chances of a photon of light being scattered in a particular direction $\theta$.

So far, the theories discussed are for single-particle and when it comes to ensembles of particles, it will become very complicated if we study the particle one by one. However, commonly the average distance between particles is large enough compared to the particle size. It can be assumed that the total scattered intensity is the sum of the intensities scattered by individual particles. As a result, we can apply single-particle scattering theory to scattering of ensembles of particle and this assumption is reasonable even for the most concentrated atmospheric conditions (Seinfeld and Pandis, 2006).

To figure out the situations of absorption and scattering of radiation by the particles, radiative transfer models (RTMs) are developed. These models simulate radiative transfer processes of the atmosphere at a given wavelength based on different atmospheric and surface's conditions (Saulo, 2008). For different surface conditions, there are leaf RTMs, canopy RTMs and combined RTMs to simulate how radiation interact with these surfaces (Verrelst and Rivera, 2014). For how radiation interact with atmosphere, there are three RTMs to simulate. 
The details are showed in the figure below (Verrelst and Rivera, 2014).

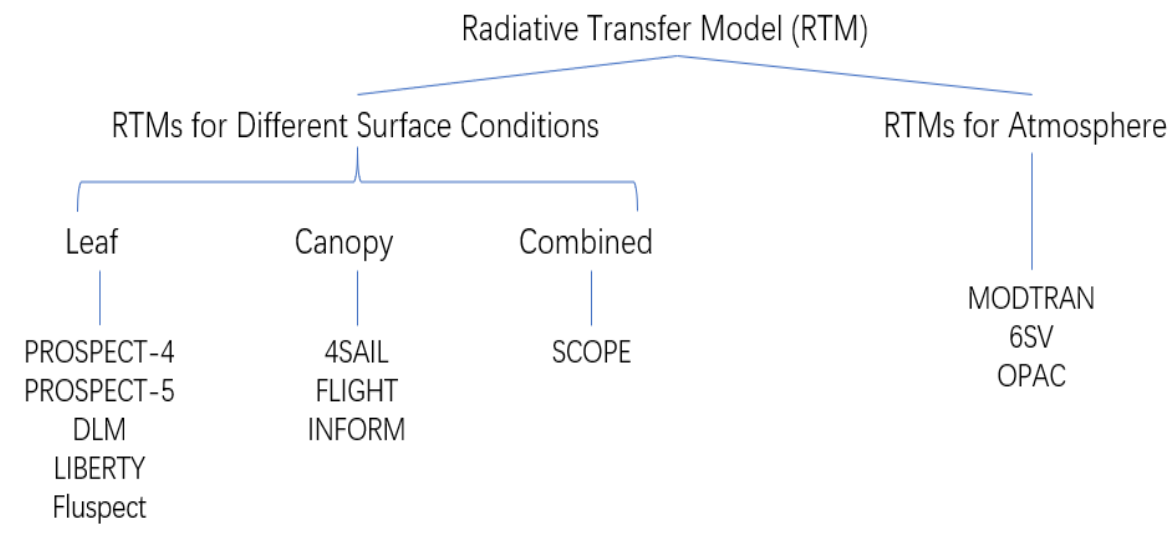

\section{Figure 5: Different Radiative Transfer Models (Concluded from Verrelst and Rivera, 2014)}

After being impacted by the particles in the air, light is 'weakened or blocked' and thus visibility is reduced. Visibility degradation is one of the best indicators for air pollution (Seinfeld and Pandis, 2006). When air is polluted and many fine particles are there, light is absorbed and scattered a lot by those particles, which is heavily responsible for visibility degradation (Seinfeld and Pandis, 2006).

To sum up the interactions between radiation and atmospheric aerosols and the effects they might bring, the direct radiative effect should be considered first. Due to the large number of aerosols and long lifetime of some of them in atmosphere, they are favorable materials to increase the reflectivity of the earth and thus provide a "screen" for the earth (Christensen et al, 2016). Although they can also absorb radiation and heat the atmosphere, the direct radiative effect turns out to be cooling as they can "block" more radiation than they can absorb to heat for the earth (Allen et al, 2016). In addition, aerosols will absorb water in the atmosphere to become cloud condensation nuclei and eventually generate clouds, which is the indirect radiative effect of aerosols. This indirect radiative effect cools the earth much more than the direct radiative effect of aerosols (Allen et al, 2016). Besides, since the aerosols are predicted to be increased in the future, the net cooling effect will consequently be enhanced (Allen et al, 2016).

\section{Environmental policy and solution}

\subsection{Climate change legislation around the world}

When it comes to $21^{\text {st }}$ century, climate change has attracted lots of attention and thus many countries began to make laws and policies to mitigate it. Most laws and policies related to climate change were carried out between 2009 and 2016, accounting for about 40 percent of total number of all climate change laws and 
policies introduced in that period (Nachmany et al, 2019). As the climate change is becoming more and more significant and received much attention, the Paris Agreement was announced and adopted in 2015, which was considered as a landmark of climate change adaptation. After that, over 160 countries around the world had commitments to control their emissions through their nationally determined contributions (NDCs) and there are over 1,300 national laws related to the climate change mitigation and adaptation in the world nowadays (Averchenkova et al, 2017). Besides legislations around the world, litigations related to climate change are increasing in number and range, some of which have even expanded to countries with low or middle incomes (Setzer and Byrnes, 2019). This phenomenon shows more and more countries even the developing countries are concerned about climate change and want to make adaptation and mitigation.

From the perspective of aerosols, it is sure that anthropogenic aerosols are mainly come from the emission of human activities like industrial production and transportation so the policies and laws which are made to control the emission of greenhouse gas will have great impact on aerosol emission as well (Zhao et al, 2019). As a result, aerosol production is being cut down with the control of emission and the impacts that aerosols have on climate began to decrease after the wide legislation of climate change (Zhao et al, 2019).

\subsection{Potential solutions}

Generally, solutions to climate change can be divided into two parts, namely mitigation and adaptation (Shaftel, 2020). Mitigation represents all the ways to reduce and slow down the climate change including cutting down emission of greenhouse gases and developing approaches to 'sink' greenhouse gases which will thus reduce the global warming brought by those gases. The goals of mitigation are to avoid strong human interference with eco-system and stabilize or reduce the level of greenhouse gases in a sufficient timeframe which makes the eco-system able to neutralize climate change brought by human (IPCC, 2014). Although aerosol emission reduction associated with climate change mitigation policy is having a warming effect on climate change due to the overall cooling effect of aerosols, the warming by aerosol reduction will be negligible at the end of this century (Hienola et al, 2018). On the other hand, human needs to adapt to live in the earth under climate change, which is so-called adaptation mentioned in the beginning. Adaptation means not only to get used to actual climate but also to adjust the living and production plan to future climate (Shaftel, 2020). This includes trying our best to avoid harmful impact brought by climate change and to make use of the benefits brought by it such as extended growing seasons for crops (Shaftel, 2020). Meanwhile, publicity of the concerns about climate change is of great importance. 
The serious situation of climate change should be widely spread to common citizens to raise their awareness, making them take actions in daily life. Also, law and policy maker should be informed by some official reports like IPCC. It is a driver to lay out laws and policies which might change the framework of living and production into a more environmental-friendly one (Averchenkova et al, 2017).

\section{References}

[1] IPCC, 2018: Summary for Policymakers. In: Global Warming of $1.5^{\circ} \mathrm{C}$. An IPCC Special Report on the impacts of global warming of $1.5^{\circ} \mathrm{C}$ above preindustrial levels and related global greenhouse gas emission pathways, in the context of strengthening the global response to the threat of climate change, sustainable development, and efforts to eradicate poverty [Masson-Delmotte, V., P. Zhai, H.-O. Pörtner, D. Roberts, J. Skea, P.R. Shukla, A. Pirani, W. Moufouma-Okia, C. Péan, R. Pidcock, S. Connors, J.B.R. Matthews, Y. Chen, X. Zhou, M.I. Gomis, E. Lonnoy, T. Maycock, M. Tignor, and T. Waterfield (eds.)]. In Press.

[2] World Meteorological Organization (2020). WMO Statement on the State of the Global Climate in 2019. WMO-No. 1248. Geneva. ISBN 978-92-6311248-4.

[3] Seinfeld, John H., and Spyros N. Pandis. Atmospheric Chemistry and Physics: From Air Pollution to Climate Change. New York: Wiley Interscience, 2006.

[4] Laidler, K. J., \& Meiser, J. H. (1982). Physical chemistry. Menlo Park, Calif: Benjamin/Cummings Pub. Co. ISBN 0-8053-5682-7.

[5] Hidy, G. (1984). Chapter 3 Particle Clouds: the Size Distribution Function. In Aerosols, an Industrial and environmental science (pp. 57-97). Academic Press.

[6] Fuchs, N. A. (1964). The Mechanics of Aerosols. Oxford: Pergamon Press.

[7] Bohren, C. F., \& Huffman, D. R. (1983). Absorption and scattering of light by small particles. Wiley.

[8] Averchenkova, A., Fankhauser, S., \& Nachmany, M. (2017). Trends in climate change legislation. Edward Elgar Publishing.

[9] IPCC, 2014: Summary for Policymakers. In: Climate Change 2014: Mitigation of Climate Change. Contribution of Working Group III to the Fifth Assessment Report of the Intergovernmental Panel on Climate Change [Edenhofer, O., R. Pichs-Madruga, Y. Sokona, E. Farahani, S. Kadner, K. Seyboth, A. Adler, I. Baum, S. Brunner, P. Eickemeier, B. Kriemann, J. Savolainen, S. Schlömer, C. von Stechow, T. Zwickel and J.C. Minx (eds.)]. Cambridge University Press, Cambridge, United Kingdom and New York, NY, USA.

[10] Stone, D., Allen, M. R., Selten, F., Kliphuis, M., \& Stott, P. A. (2007). The Detection and Attribution of Climate Change Using an Ensemble of Opportunity, Journal of Climate, 20(3), 504-516.

[11] Kiehl, J. T., \& Trenberth, K. E. (1997). Earth's Annual Global Mean Energy Budget, Bulletin of the American Meteorological Society, 78(2), 197-208. 
[12] Penner, J., Andreae, M., Annegarn, H., Barrie, L., Feichter, J., Hegg, D., Jayaraman, A., Leaitch, R., Murphy, D., Nganga, J. and Pitari, G. (2001). Aerosols, their Direct and Indirect Effects. Climate Change 2001: The Scientific Basis. Contribution of Working Group I to the Third Assessment Report of the Intergovernmental Panel on Climate Change, 289-348.

[13] Karagulian, F., Belis, C. A., Dora, C. F., Prüss-Ustün, A. M., Bonjour, S., Adair-Rohani, H., \& Amann, M. (2015). Contributions to cities' ambient particulate matter (PM): A systematic review of local source contributions at global level. Atmospheric Environment, 120, 475-483. https://doi.org/10.1016/j.atmosenv.2015.08.087

[14] Finlay, S. E., Moffat, A., Gazzard, R., Baker, D., \& Murray, V. (2012). Health impacts of wildfires. PLoS currents, 4, e4f959951cce2c. https://doi.org/10.1371/4f959951cce2c

[15] Stott, P. A., Gillett, N. P., Hegerl, G. C., Karoly, D. J., Stone, D. A., Zhang, X., \& Zwiers, F. (2010). Detection and attribution of climate change: a regional perspective. Wiley Interdisciplinary Reviews: Climate Change, 1(2), 192-211. https://doi.org/10.1002/wcc.34

[16] Allen, R. J., Landuyt, W., \& Rumbold, S. T. (2015). An increase in aerosol burden and radiative effects in a warmer world. Nature Climate Change, 6(3), 269-274. https://doi.org/10.1038/nclimate2827

[17] Andreae, M. O., Jones, C. D., \& Cox, P. M. (2005). Strong present-day aerosol cooling implies a hot future. Nature, 435(7046), 1187-1190. https://doi.org/10.1038/nature03671

[18] Elkins, J., Thompson, T., Swanson, T. et al. (1993). Decrease in the growth rates of atmospheric chlorofluorocarbons 11 and 12. Nature 364, 780-783. https://doi.org/10.1038/364780a0

[19] Hickey, J., Alton, B., Kyle, H., \& Hoyt, D. (1988). Total solar irradiance measurements by ERB/Nimbus-7. A review of nine years. Space Science Reviews, 48(3-4). https://doi.org/10.1007/bf00226011

[20] Rabha, S., \& Saikia, B. K. (2020). Advanced micro- and nanoscale characterization techniques for carbonaceous aerosols. Handbook of Nanomaterials in Analytical Chemistry, 449-472. https://doi.org/10.1016/b978-0-12-816699-4.00018-9

[21] Christensen, M. W., Chen, Y.-C., \& Stephens, G. L. (2016). Aerosol indirect effect dictated by liquid clouds. Journal of Geophysical Research: Atmospheres, 121(24). https://doi.org/10.1002/2016jd025245

[22] Liu, B., Szymanski, W., \& Ahn, K.-H. (1985). On Aerosol Size Distribution Measurement by Laser and White Light Optical Particle Counters. Journal of the IEST, 28(3), 19-24. https://doi.org/10.17764/jiet.1.28.3.k873425806586048

[23] Martin, S. T. (2000). Phase Transitions of Aqueous Atmospheric Particles. Chemical Reviews, 100(9), 3403-3454. https://doi.org/10.1021/cr990034t

[24] Young, A. T. (1981). Rayleigh scattering. Applied Optics, 20(4), 533. https://doi.org/10.1364/ao.20.000533 
[25] Zhao, A., Bollasina, M. A., Crippa, M., \& Stevenson, D. S. (2019). Significant climate impacts of aerosol changes driven by growth in energy use and advances in emission control technology. Atmospheric Chemistry and Physics, 19(23), 14517-14533. https://doi.org/10.5194/acp-19-14517-2019

[26] Hienola, A., Partanen, A.-I., Pietikäinen, J.-P., O’Donnell, D., Korhonen, H., Matthews, H. D., \& Laaksonen, A. (2018). The impact of aerosol emissions on the $1.5^{\circ} \mathrm{C}$ pathways. Environmental Research Letters, 13(4), 044011. https://doi.org/10.1088/1748-9326/aab1b2

[27] Setzer, J. and Byrnes, R. (2019). Global trends in climate change litigation: 2019 snapshot. London: Grantham Research Institute on Climate Change and the Environment and Centre for Climate Change Economics and Policy, London School of Economics and Political Science.

https://www.lse.ac.uk/granthaminstitute/publication/global-trends-in-climatechange-litigation-2019-snapshot/

[28] Nachmany, M., Byrnes, R., \& Surminski, S. (2019, December). National laws and policies on climate change adaptation: A global review. London: Grantham Research Institute on Climate Change and the Environment and Centre for Climate Change Economics and Policy, London School of Economics and Political Science.

https://www.lse.ac.uk/granthaminstitute/publication/national-laws-andpolicies-on-climate-change-adaptation-a-global-review/

[29] Bowden, J. (2019, October 22). Ozone hole shrinks to lowest size since 1982, unrelated to climate change: NASA. The Hill. https://thehill.com/policy/energy-environment/466792-ozone-hole-shrinksto-lowest-size-since-1982-unrelated-to-climate.

[30] Nave, C. (2001). Blue Sky. Retrieved September 27, 2020, from http://hyperphysics.phy-astr.gsu.edu/hbase/atmos/blusky.html

[31] Saulo, C. (2008). Radiative Transfer Models. Retrieved October 24, 2020, from http://4dvarenkf.cima.fcen.uba.ar/course/download/Saulo_RTmodels.pdf

[32] Verrelst, J. and Rivera, J. P. (2014). Radiative Transfer Models. Retrieved October 23, 2020, from https://artmotoolbox.com/radiative-transfermodels.html

[33] Shaftel, H., Jackson, R., Callery, S., \& Bailey, D. (Eds.). (2020, September 18). Climate Change Adaptation and Mitigation. NASA. Retrieved November 04, 2020, from https://climate.nasa.gov/solutions/adaptation-mitigation/ 